Article

\title{
Dental Resin Cements-The Influence of Water Sorption on Contraction Stress Changes and Hydroscopic Expansion
}

\author{
Grzegorz Sokolowski ${ }^{1}$, Agata Szczesio ${ }^{2}{ }^{(\mathbb{D}}$, Kinga Bociong ${ }^{2}$, Karolina Kaluzinska ${ }^{2}$, \\ Barbara Lapinska $^{3}$ iD ${ }^{\text {, Jerzy Sokolowski }}{ }^{3}$, Monika Domarecka ${ }^{3}$ and \\ Monika Lukomska-Szymanska ${ }^{3, *}$ \\ 1 Department of Prosthetic Dentistry, Medical University of Lodz, 251 Pomorska St., 92-213 Lodz, Poland; \\ grzegorz.sokolowski@umed.lodz.pl \\ 2 University Laboratory of Materials Research, Medical University of Lodz, 251 Pomorska St., 92-213 Lodz, \\ Poland; agata.szczesio@umed.lodz.pl (A.S.); kinga.bociong@umed.lodz.pl (K.B.); \\ karolina.kaluzinska@umed.lodz.pl (K.K.) \\ 3 Department of General Dentistry, Medical University of Lodz, 251 Pomorska St., 92-213 Lodz, Poland; \\ barbara.lapinska@umed.lodz.pl (B.L.); jerzy.sokolowski@umed.lodz.pl (J.S.); \\ monika.domarecka@umed.lodz.pl (M.D.) \\ * Correspondence: monika.lukomska-szymanska@umed.lodz.pl; Tel.: +48-42-675-74-64
}

Received: 14 May 2018; Accepted: 6 June 2018; Published: 8 June 2018

\begin{abstract}
Resin matrix dental materials undergo contraction and expansion changes due to polymerization and water absorption. Both phenomena deform resin-dentin bonding and influence the stress state in restored tooth structure in two opposite directions. The study tested three composite resin cements (Cement-It, NX3, Variolink Esthetic DC), three adhesive resin cements (Estecem, Multilink Automix, Panavia 2.0), and seven self-adhesive resin cements (Breeze, Calibra Universal, MaxCem Elite Chroma, Panavia SA Cement Plus, RelyX U200, SmartCem 2, and SpeedCEM Plus). The stress generated at the restoration-tooth interface during water immersion was evaluated. The shrinkage stress was measured immediately after curing and after $0.5 \mathrm{~h}, 24 \mathrm{~h}, 72 \mathrm{~h}, 96 \mathrm{~h}, 168 \mathrm{~h}, 240 \mathrm{~h}$, $336 \mathrm{~h}, 504 \mathrm{~h}, 672 \mathrm{~h}$, and $1344 \mathrm{~h}$ by means of photoelastic study. Water sorption and solubility were also studied. All tested materials during polymerization generated shrinkage stress ranging from 4.8 MPa up to $15.1 \mathrm{MPa}$. The decrease in shrinkage strain (not less than $57 \%$ ) was observed after water storage (56 days). Self-adhesive cements, i.e., MaxCem Elite Chroma, SpeedCem Plus, Panavia SA Plus, and Breeze exhibited high values of water expansion stress (from 0 up to almost $7 \mathrm{MPa}$ ). Among other tested materials only composite resin cement Cement It and adhesive resin cement Panavia 2.0 showed water expansion stress ( 1.6 and 4.8 , respectively). The changes in stress value (decrease in contraction stress or built up of hydroscopic expansion) in time were material-dependent.
\end{abstract}

Keywords: resin cements; shrinkage stress; water sorption; hydroscopic expansion; photoelastic investigation

\section{Introduction}

Resin composite cements have been widely used with ceramic, resin, or metal alloy-based prosthodontic restorations [1]. The cementation technique used in adhesive dentistry is one of the major factors, which exerts influence on the clinical success of indirect restorative procedures. Cement is used to bond tooth and restoration simultaneously creating a barrier against microbial leakage [2]. The universal cement that can be applied in all indirect restorative procedures has not been introduced into 
the market yet. Therefore, clinicians should understand the influence of applied material properties and preparation design on the clinical performance of the restoration [3].

The composition of resin composite cements is almost the same as of resin composites [4]. Resin cements mainly consist of various methacrylate resins and inorganic fillers which are often coated with organic silanes to provide adhesion between the filler and the matrix. These materials often include bonding agents to promote the adhesion between resin cement and tooth structure. Main monomers are, i.e., hydroxyethyl methacrylate (HEMA), 4-methacryloyloxyethy trimellitate anhydride (4-MET), carboxylic acid, and organophospate 10-methacryloxydecyl dihydrogen phosphate (10-MDP) (Figure 1). The acidic group bonds calcium ions in the tooth structure $[5,6]$.<smiles>C=C(C)C(=O)OCCOC(=O)c1ccc2c(c1)C(=O)OC2=O</smiles><smiles>C=C(C)C(=O)OCCCCCCCCCCOP(=O)(O)O</smiles>

Figure 1. Monomers used as bonding agents in resin cements.

Resin composite cements are used in combination with adhesive systems. This procedure aims at creating micro-mechanical retention to both enamel and dentin. The material may also form a strong adhesion to an adequately-treated surface of the composite, ceramic, and metallic restorations [7]. Taking into account the surface preparation before the cementation process, resin cements can be divided into: (1) composite resin cement (used with total-etch adhesive systems); (2) adhesive resin cement (used with separate self-etching adhesive systems); and (3) self-adhesive resin cement (containing a self-adhesive system) [1].

The application of resin matrix-based cements is time-consuming and susceptible to manipulation errors [8]. The self-adhesive resin cements are proposed to simplify the restoration procedure. These materials bond dentin in one step without any surface conditioning or pre-treatment (priming) $[9,10]$.

All currently available resin-based materials exhibit polymerization shrinkage. Moreover, resin cements are generally applied as a thin layer, particularly when used to lute posts, inlays, and crowns. In the aforementioned clinical cases, the cavity design has a high C-factor (high number of bonded surfaces and a low number of un-bonded surfaces) [11]. Additionally, low-viscosity composites exhibit a relatively high shrinkage amounting up to $6 \%$ (comparable to resin cements) [12,13]. These factors may generate sufficient stress resulting in debonding of the luting material, thereby increasing microleakage [14]. Nevertheless, there is little data on the stress generated by these materials. The sorption characteristic of resin-based dental cements has been extensively evaluated [15-17]. However, the analysis of the influence of water sorption on the change in contraction stress is inadequate. The purpose of this study was to evaluate the development of the stress state, i.e., the contraction stress generated during photopolymerization and hydroscopic expansion within different types of resin cements which undergo water ageing by means of photoelastic analysis.

\section{Materials and Methods}

The composition of investigated resin cements and bonding systems is presented in Tables 1 and 2. 
Table 1. The composition of resin cements.

\begin{tabular}{|c|c|c|c|c|}
\hline Material & Type & Composition & Curing Time (s) & Manufacturer \\
\hline Cement-It & Composite resin cement & bis-GMA, UDMA, HDDMA, PEGDMA, barium-boro-silicate glass (65 wt \%) & 20 & $\begin{array}{c}\text { Jeneric Pentron } \\
\text { (Wallingford, CT, USA) }\end{array}$ \\
\hline NX3 & Composite resin cement & $\begin{array}{l}\text { TEGDMA, bis-GMA, fluoro-aluminosilicate glass ( } 67.5 \mathrm{wt} \% / 47 \mathrm{vol} \%) \text {, activators, stabilizers, } \\
\text { radiopaque agent }\end{array}$ & 20 & $\begin{array}{l}\text { Kerr (Orange, } \\
\text { CA, USA) }\end{array}$ \\
\hline $\begin{array}{l}\text { Variolink Esthetic } \\
\text { DC }\end{array}$ & Composite resin cement & $\begin{array}{l}\text { UMDA and further methacrylate monomers, ytterbium trifluoride, spheroid mixed oxide } \\
\qquad(67 \mathrm{wt} \% / 38 \mathrm{vol} \%) \text {, initiators, stabilizers and pigments }\end{array}$ & 10 & $\begin{array}{l}\text { Ivoclar Vivadent } \\
\text { (Ellwangen, Germany) }\end{array}$ \\
\hline Estecem & Adhesive resin cement & bis-GMA, TEGDMA, bis-MPEPP, silica-zirconia filler (74 wt \%), camphorquinone & 20 & $\begin{array}{l}\text { Tokuyama Dental } \\
\text { (Taitou, Japan) }\end{array}$ \\
\hline Multilink Automix & Adhesive resin cement & $\begin{array}{l}\text { dimethacrylate and HEMA, barium glass and silica filler, ytterbiumtrifluoride (68 wt \%), } \\
\text { catalysts, stabilizers, pigments }\end{array}$ & 10 & $\begin{array}{l}\text { Ivoclar Vivadent } \\
\text { (Ellwangen, Germany) }\end{array}$ \\
\hline Panavia 2.0 & Adhesive resin cement & $\begin{array}{l}\text { 10-MDP, BPEDMA, hydrophobic aliphatic metahrylates, hydrophilic aliphatic metahrylate, } \\
\text { silanated silica filler, silanated barium glass filler, sodium fluoride }(70.8 \mathrm{wt} \%)\end{array}$ & 20 & $\begin{array}{l}\text { Kuraray (Osaka, } \\
\text { Japan) }\end{array}$ \\
\hline Breeze & Self-adhesive resin cement & $\begin{array}{l}\text { bis-GMA, UDMA, TEGDMA, HEMA, 4-MET, silane treated barium glass, silica, BiOCl, } \\
\text { Ca-Al-F-silicate, curing system }\end{array}$ & 20 & $\begin{array}{l}\text { Jeneric Pentron } \\
\text { (Wallingford, CT, USA) }\end{array}$ \\
\hline Calibra Universal & Self-adhesive resin cement & $\begin{array}{l}\text { UDMA, trimethylolpropane trimethacrylate TMPTMA, bis-EMA-Bisphenol A ethoxylate } \\
\text { dimethacrylate, TEGDMA, HEMA, 3-(acryloyloxy)-2-hydroxypropyl methacrylate, urethane } \\
\text { modified bis-GMA, PENTA, silanated barium glass, fumed silica ( } 48 \text { vol \%) }\end{array}$ & 10 & $\begin{array}{l}\text { Dentsply Sirona (York, } \\
\text { PA, USA) }\end{array}$ \\
\hline $\begin{array}{l}\text { MaxCem Elite } \\
\text { Chroma }\end{array}$ & Self-adhesive resin cement & $\begin{array}{l}\text { HEMA, GDM, UDMA, 1,1,3,3-tetramethylbutyl hydroperoxide TEGDMA, } \\
\text { fluoroaluminosilicate glass, GPDM, barium glass filler, fumed silica (69 wt \%) }\end{array}$ & 10 & $\begin{array}{l}\text { Kerr (Orange, } \\
\text { CA, USA) }\end{array}$ \\
\hline $\begin{array}{l}\text { Panavia SA } \\
\text { Cement Plus }\end{array}$ & Self-adhesive resin cement & $\begin{array}{l}\text { bis-GMA, TEGDMA, HEMA, 10-MDP, hydrophobic aromatic dimethacrylate, hydrophobic } \\
\text { aliphatic dimethacrylate, sodium fluoride, silanated barium glass filler, silanated colloidal } \\
\text { silica ( } 70 \mathrm{wt} \% / 40 \text { vol } \%)\end{array}$ & 10 & $\begin{array}{l}\text { Kuraray (Osaka, } \\
\text { Japan) }\end{array}$ \\
\hline RelyX U200 & Self-adhesive resin cement & $\begin{array}{c}\text { methacrylate monomers containing phosphoric acid groups, methacrylate monomers, } \\
\text { silanated fillers ( } 70 \mathrm{wt} \% / 43 \mathrm{vol} \%) \text {, initiator components, stabilizers, rheological additives, } \\
\text { alkaline(basic) initiator components, stabilizers, pigments }\end{array}$ & 20 & $\begin{array}{l}\text { 3M ESPE (St. Paul, } \\
\text { MN, USA) }\end{array}$ \\
\hline SmartCem 2 & Self-adhesive resin cement & $\begin{array}{l}\text { UDMA, urethane modified bis-GMA, TEGDMA, PENTA, dimethacrylate resins, barium } \\
\text { boron fluoroaluminosilicate glass amorphous silica }(69 \mathrm{wt} \% / 46 \mathrm{vol} \%)\end{array}$ & 10 & $\begin{array}{l}\text { Dentsply Sirona (York, } \\
\text { PA, USA) }\end{array}$ \\
\hline SpeedCEM Plus & Self-adhesive resin cement & $\begin{array}{l}\text { UDMA, TEGDMA, PEGDMA, methacrylated phosphoric acid ester, 1,10-decandiol } \\
\text { dimethacrylate, copolymers, dibenzoyl peroxide, ytterbium trifluoride, barium glass, silicon } \\
\text { dioxide }(75 \mathrm{wt} \% / 45 \mathrm{vol} \%)\end{array}$ & 20 & $\begin{array}{l}\text { Ivoclar Vivadent } \\
\text { (Ellwangen, Germany) }\end{array}$ \\
\hline \multicolumn{5}{|c|}{$\begin{array}{l}\text { bis-GMA-bisphenol A glycol dimethacrylate, UDMA-urethane dimethacrylate, TEGDMA-triethylene glycol dimethacrylate, GDM-glycerol 1,3-dimethacrylate, } \\
\text { GPDM-glycerol phosphate dimethacryalte, bis-MPEPP-bisphenol A polyethoxy methacrylate, HEMA-hydroxyethyl methacrylate, PEGDMA-polyethylene glycol } \\
\text { dimethacrylate, NPGDMA-neopentyldimethacrylate, 10-MDP-10-methacryloxydecyl dihydrogen phosphate, BPEDMA-bisphenol-A-polyethoxy dimethacrylate, } \\
\text { PENTA-dipentaerythritol penttacrylate monophosphate, HDDMA-1,6-hexanediol dimethacrylate, 4-MET-4-methacryloyloxyethy trimellitate anhydride, } \\
\text { MAC-10-11-methacryloyloxy-11-undecanedicarbxylic acid. }\end{array}$} \\
\hline
\end{tabular}


Table 2. The curing time of bonding systems.

\begin{tabular}{cccc}
\hline Bonding system & Manufacturer & Curing Time (s) & Bonding System Dedicated to \\
\hline $\begin{array}{c}\text { Bond-1 C\&B } \\
\text { Primer/Adhesive }\end{array}$ & $\begin{array}{c}\text { Jeneric Pentrton } \\
\text { (Wallingford, CT, USA) }\end{array}$ & 10 & Cement It, Breeze \\
\hline Clearfil SE bond & Kuraray (Osaka, Japan) & 10 & $\begin{array}{c}\text { Panavia 2.0, Panavia SA } \\
\text { Cement Plus }\end{array}$ \\
\hline Easy Bond & $\begin{array}{c}\text { 3M ESPE (St. Paul, } \\
\text { MN, USA) }\end{array}$ & 10 & RelyX U200 \\
\hline Estelink & $\begin{array}{c}\text { Tokuyam Dental } \\
\text { (Taitou, Japan) }\end{array}$ & 10 & Estecem \\
\hline Monobond Plus & $\begin{array}{c}\text { Ivoclar Vivadent } \\
\text { (Ellwangen, Germany) }\end{array}$ & 10 & $\begin{array}{c}\text { Variolink Esthetic DC, Multilink } \\
\text { Automix, SpeedCEM Plus }\end{array}$ \\
\hline OptiBond XRT & Kerr (Orange, CA, USA) & 10 & NX3, MaxCem Elite Chroma \\
\hline $\begin{array}{c}\text { Prime\&Bond Elect } \\
\text { Universal }\end{array}$ & $\begin{array}{c}\text { Dentsply Sirona (York, } \\
\text { PA, USA) }\end{array}$ & 10 & SmartCem 2, Calibra Universal \\
\hline
\end{tabular}

\subsection{Absorbency Dynamic Study}

Absorbency dynamic was determined by means of procedure as described by Bociong et al. [18]. The samples were prepared according to ISO 4049 [19]. Curing time was consistent with the manufacturer's instructions (Table 2).

In order to characterize absorbency dynamic, the cylindrical samples with dimensions of $15 \mathrm{~mm}$ in diameter and of $1 \mathrm{~mm}$ in width were prepared. The tested materials were applied in one layer and cured with LED light lamp (Mini L.E.D., Acteon, Mérignac Cedex, France) in nine zones partially overlapping each other with direct contact of optical fiber with the material surface. Exposure time was applied according to the manufacturer's instructions (Table 1).

Five samples were prepared for each tested cement. The samples' weight was determined (RADWAG AS 160/C/2, Poland) immediately after preparation and then for 30 consecutive days, and after $1344 \mathrm{~h}$ (56 days) and $2016 \mathrm{~h}$ (84 days). The absorbency was calculated according to the Equation (1) [20]:

$$
\mathrm{A}=\frac{\mathrm{m}_{\mathrm{i}}-\mathrm{m}_{0}}{\mathrm{~m}_{0}} \cdot 100 \%
$$

where $\mathrm{A}$ is the absorbency of water, $\mathrm{m}_{0}$ is the mass of the sample in dry condition, and $\mathrm{m}_{\mathrm{i}}$ is the mass of the sample after storage in water for a specified (i) period of time.

\subsection{Water Sorption and Solubility}

Water sorption and solubility were investigated according to ISO 4049 [19]. The detailed procedure of tests has been described extensively in the previously published literature $[18,21]$. Curing time was consistent with the manufacturer's instructions (Table 1).

Water sorption and solubility were calculated according to following equations:

$$
\begin{aligned}
& W_{s p}=\frac{m_{2}-m_{3}}{V} \\
& W_{s l}=\frac{m_{1}-m_{3}}{V}
\end{aligned}
$$

where: $W_{s p}$ is the water sorption, $W_{s l}$ is the water solubility, $m_{1}$ is the initial constant mass $(\mu \mathrm{g}), m_{2}$ is the mass after seven days of water immersion $(\mu \mathrm{g}), m_{3}$ is the final constant mass $(\mu \mathrm{g}), V$ is the specimen volume $\left(\mathrm{mm}^{3}\right)$. 


\subsection{Photoelastic Study}

Photoelastic analysis allows for quantitative measurement and visualization of stress concentration that develops during photopolymerization or water sorption of resin composites [22,23]. The modified method enables analysis of the relationship between water sorption and the change of stress state (contraction or expansion) of resin materials. This test was described extensively in our previous articles [18,24]. Photoelastically-sensitive plates of epoxy resin (Epidian 53, Organika-Sarzyna SA, Nowa Sarzyna, Poland) were used in this study. Calibrated orifices of $3 \mathrm{~mm}$ in diameter and of $4 \mathrm{~mm}$ in depth were prepared in resin plates in order to mimic an average tooth cavity. The generated strains in the plates were visualized in circular transmission polariscope FL200 (Gunt, Barsbüttel, Germany) and photoelastic strain calculations were based on the Timoshenko equation [25].

\section{Results}

\subsection{Absorbency Dynamic Study}

Water absorbency and contraction stress mean values were presented in Figures $2-14$. The water immersion resulted in an increase in weight of all tested materials. The water sorption $(\mathrm{wt} \%)$ increased for Breeze up to three times. The lowest value of absorbency after $2016 \mathrm{~h}$ (84 days) was observed for Variolink Esthetic DC.

\subsection{Water Sorption and Solubility}

Mean values of water sorption and solubility were presented in Table 3. Maxcem Elite Chroma and Breeze exhibited the highest, while Estecem showed the lowest values of water sorption.

Table 3. Stress state before and after 2016 h (84 days) of water immersion, contraction stress drop, absorbency, and solubility of tested materials.

\begin{tabular}{|c|c|c|c|c|c|}
\hline \multirow{2}{*}{ Material } & \multicolumn{2}{|c|}{ Stress State (MPa) } & \multirow{2}{*}{$\begin{array}{c}\text { Contraction Stress } \\
\text { Drop }(\%)\end{array}$} & \multirow{2}{*}{$\begin{array}{l}\text { Sorption } \\
\left(\mu \mathrm{g} / \mathrm{mm}^{3}\right)\end{array}$} & \multirow{2}{*}{$\begin{array}{l}\text { Solubility } \\
\left(\mu \mathrm{g} / \mathrm{mm}^{3}\right)\end{array}$} \\
\hline & $0.5 \mathrm{~h}$ & $2016 \mathrm{~h}$ & & & \\
\hline Cement It & $10.9 \pm 2.2$ & $-1.6 \pm 0.4$ & $115 *$ & $27.8 \pm 0.8$ & $1.9 \pm 0.4$ \\
\hline NX3 & $6.3 \pm 0.1$ & $1.6 \pm 0.1$ & 79 & $23.8 \pm 0.6$ & $3.7 \pm 1.2$ \\
\hline Variolink Esthetic & $10.9 \pm 0.4$ & $4.7 \pm 0.1$ & 57 & $22.4 \pm 0.8$ & $10.0 \pm 2.0$ \\
\hline Estecem & $6.8 \pm 0.9$ & $1.6 \pm 0.2$ & 76 & $12.5 \pm 2.2$ & $4.6 \pm 1.9$ \\
\hline Multilink Automix & $12.5 \pm 0.4$ & $2.1 \pm 0.9$ & 83 & $25.3 \pm 1.5$ & $2.2 \pm 0.8$ \\
\hline Panavia 2.0 & $5.3 \pm 1.8$ & $-4.8 \pm 0.4$ & $191 *$ & $33,9 \pm 1.7$ & $11.1 \pm 1.0$ \\
\hline Breeze & $7.8 \pm 1.6$ & $-6.3 \pm 1.6$ & $180 *$ & $47.7 \pm 3.1$ & $3.1 \pm 0.5$ \\
\hline Calibra Universal & $11.1 \pm 0.7$ & $0.0 \pm 0.8$ & 100 & $30.9 \pm 1.5$ & $5.0 \pm 2.6$ \\
\hline MaxCem Elite Chroma & $10.4 \pm 0.9$ & $-6.3 \pm 0.3$ & $160 *$ & $50.4 \pm 1.3$ & $8.5 \pm 1.3$ \\
\hline Panavia SA Plus & $4.8 \pm 0.4$ & $-1.6 \pm 0.2$ & 133 * & $26.4 \pm 1.3$ & $1.7 \pm 0.4$ \\
\hline RelyX U200 & $13.5 \pm 0.8$ & $2.6 \pm 0.9$ & 81 & $29.6 \pm 1.3$ & $0.4 \pm 0.2$ \\
\hline SmartCem 2 & $15.1 \pm 0.9$ & $1.6 \pm 0.9$ & 89 & $33.0 \pm 0.9$ & $4.9 \pm 1.2$ \\
\hline SpeedCEM Plus & $11.9 \pm 1.1$ & $-1.6 \pm 0.4$ & $113 *$ & $28.2 \pm 0.5$ & $2.5 \pm 0.4$ \\
\hline
\end{tabular}

* represents materials with over-compensated polymerization stress due to water expansion.

\subsection{Photoelastic Study}

All materials exhibited shrinkage and the associated contraction stress during hardening process. The significant reduction in contraction stress was observed due to hygroscopic expansion of cements (Figures 2-16). Water ageing of six cements resulted in additional stress characterized by the opposite direction of forces. The investigated materials exhibited various contraction stress values. 


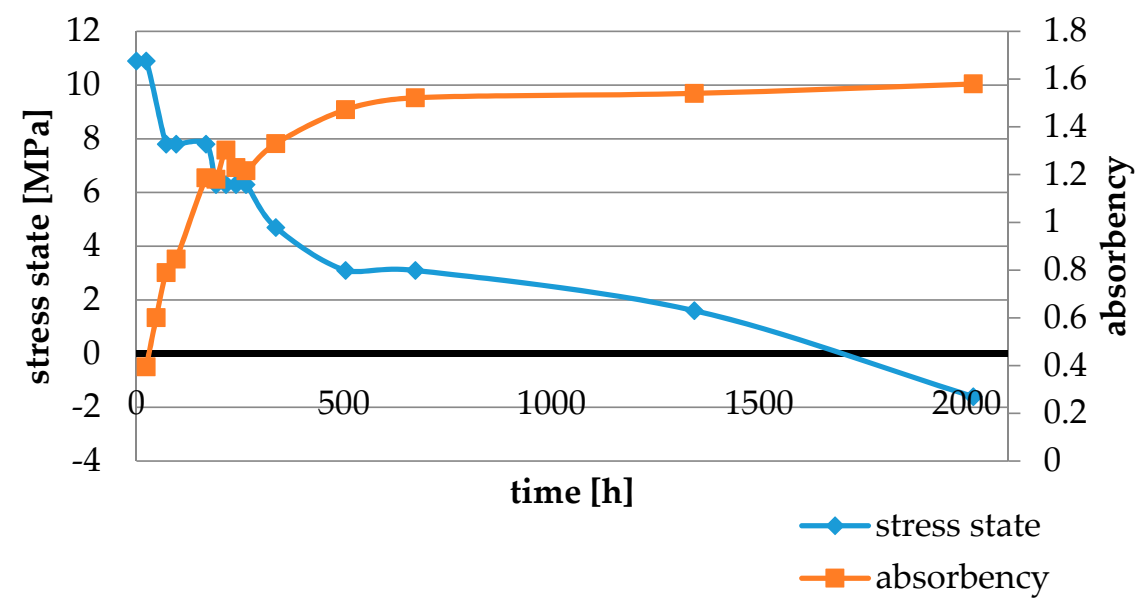

Figure 2. The influence of water sorption (2016 $\mathrm{h}$ water ageing) on the absorbency and contraction stress generated during the photopolymerization of Cement It.

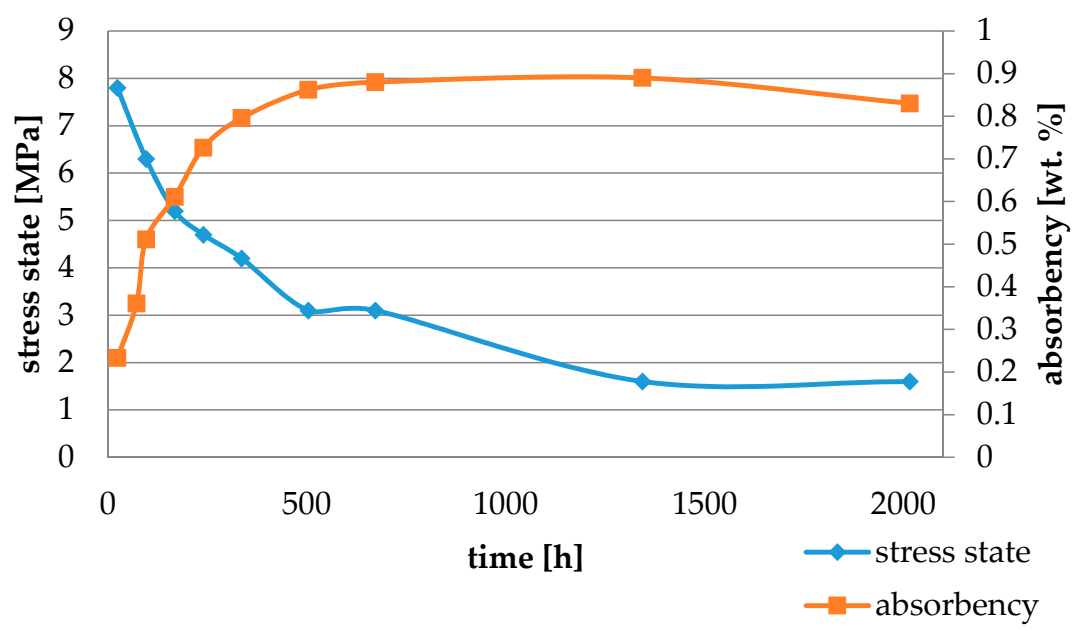

Figure 3. The influence of water sorption ( $2016 \mathrm{~h}$ water ageing) on the absorbency and contraction stress generated during the photopolymerization of NX3.

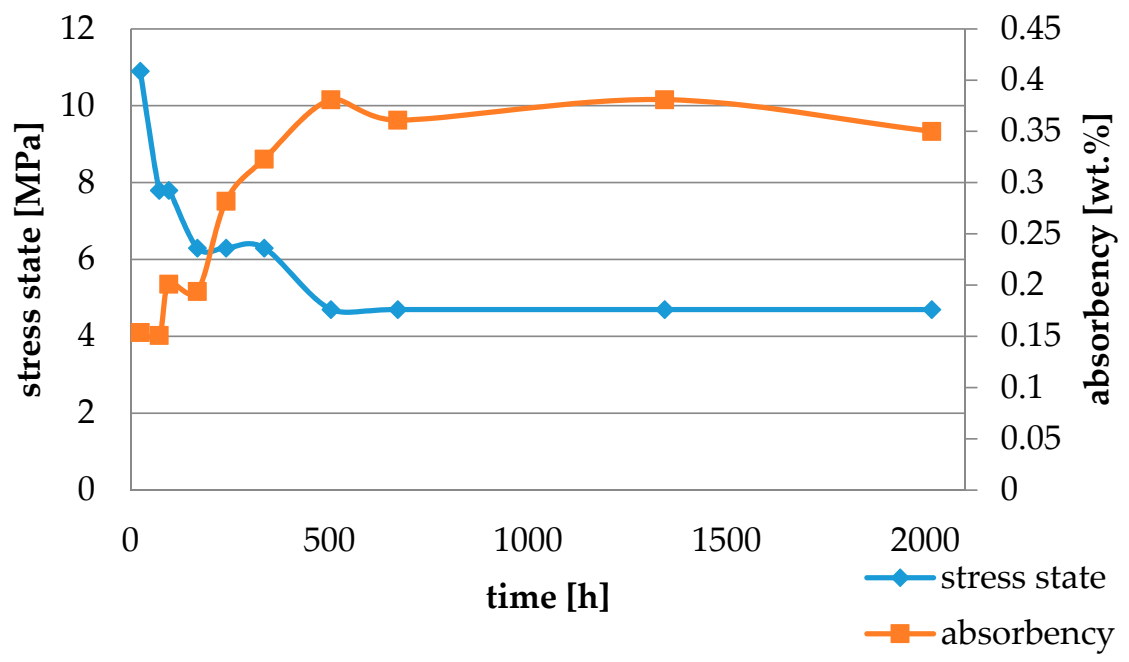

Figure 4. The influence of water sorption (2016 h water ageing) on the absorbency and contraction stress generated during the photopolymerization of Variolink Esthetic DC. 


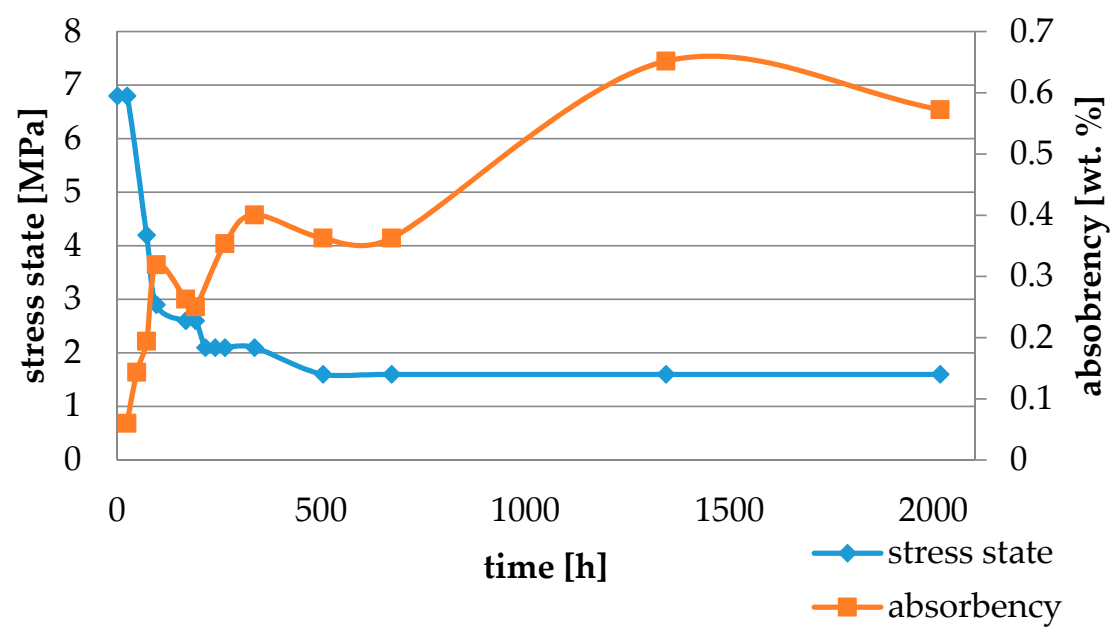

Figure 5. The influence of water sorption (2016 $\mathrm{h}$ water ageing) on the absorbency and contraction stress generated during the photopolymerization of Estecem.

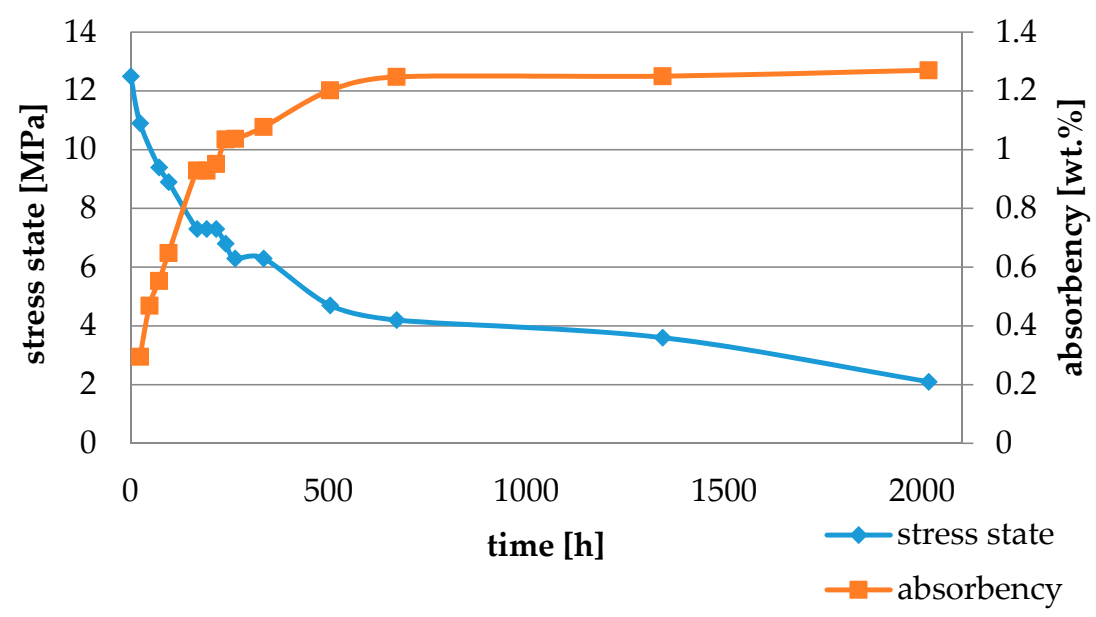

Figure 6. The influence of water sorption (2016 h water ageing) on the absorbency and contraction stress generated during the photopolymerization of Multilink Automix.

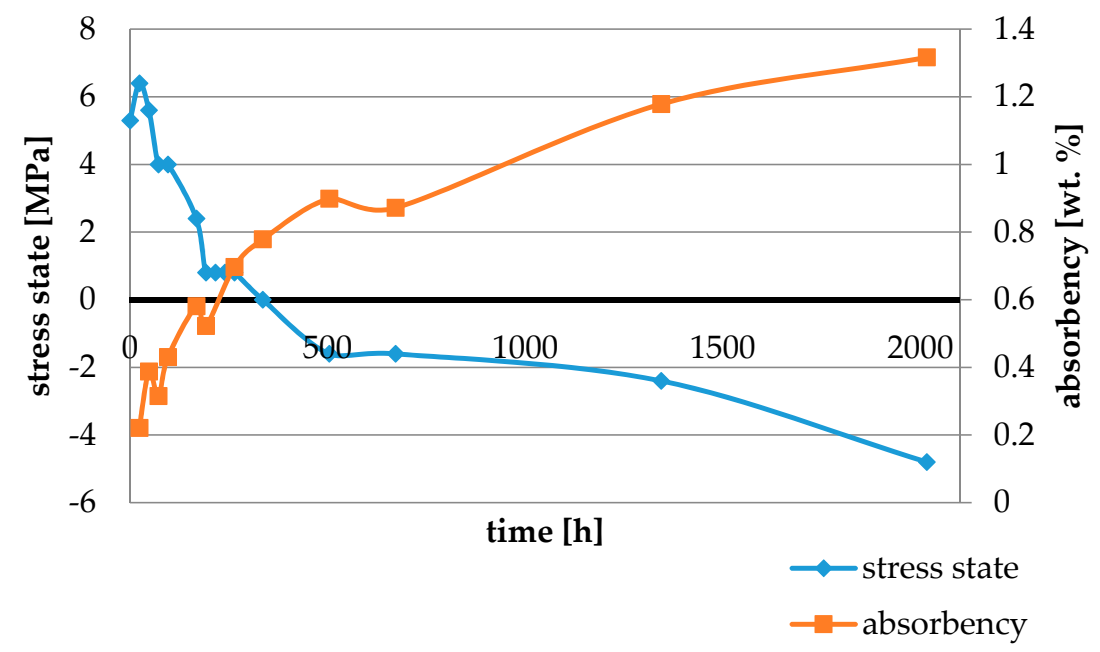

Figure 7. The influence of water sorption (2016 h water ageing) on the absorbency and contraction stress generated during the photopolymerization of Panavia 2.0. 


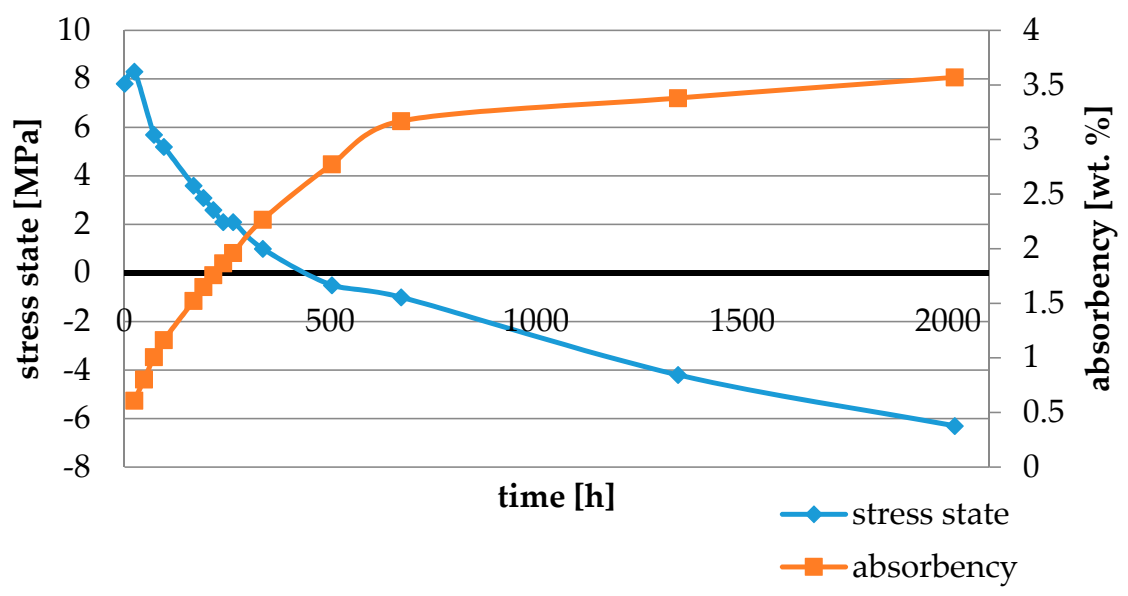

Figure 8. The influence of water sorption ( $2016 \mathrm{~h}$ water ageing) on the absorbency and contraction stress generated during the photopolymerization of Breeze.

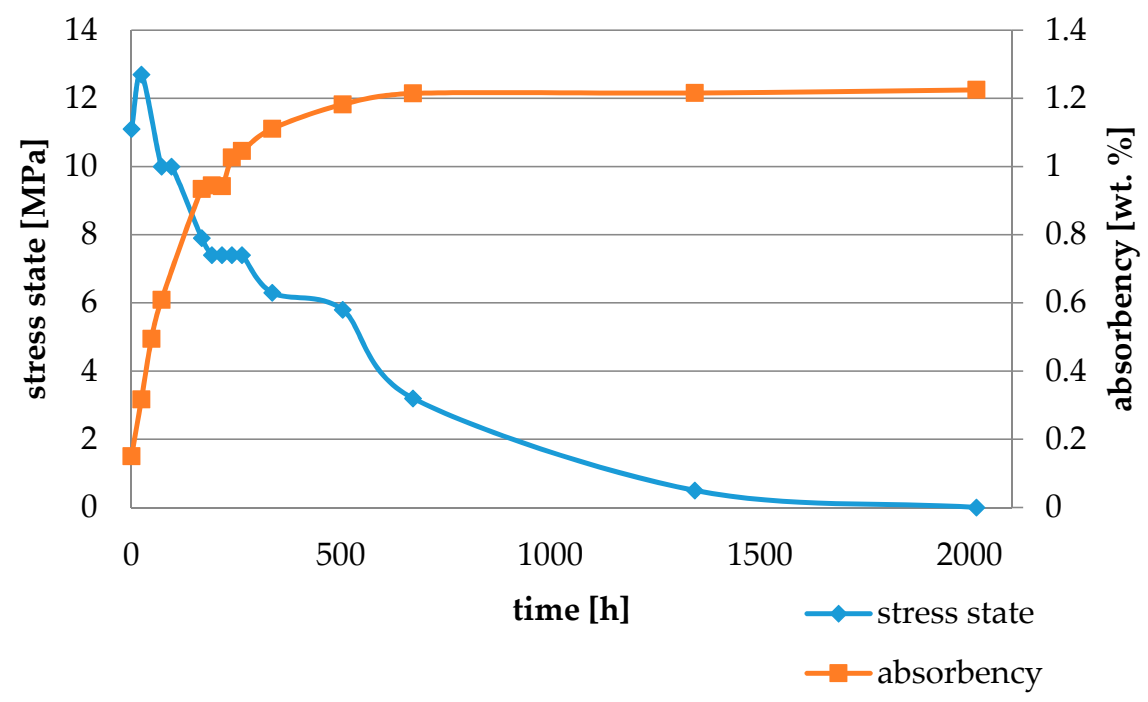

Figure 9. The influence of water sorption ( $2016 \mathrm{~h}$ water ageing) on the absorbency and contraction stress generated during the photopolymerization of Calibra Universal.

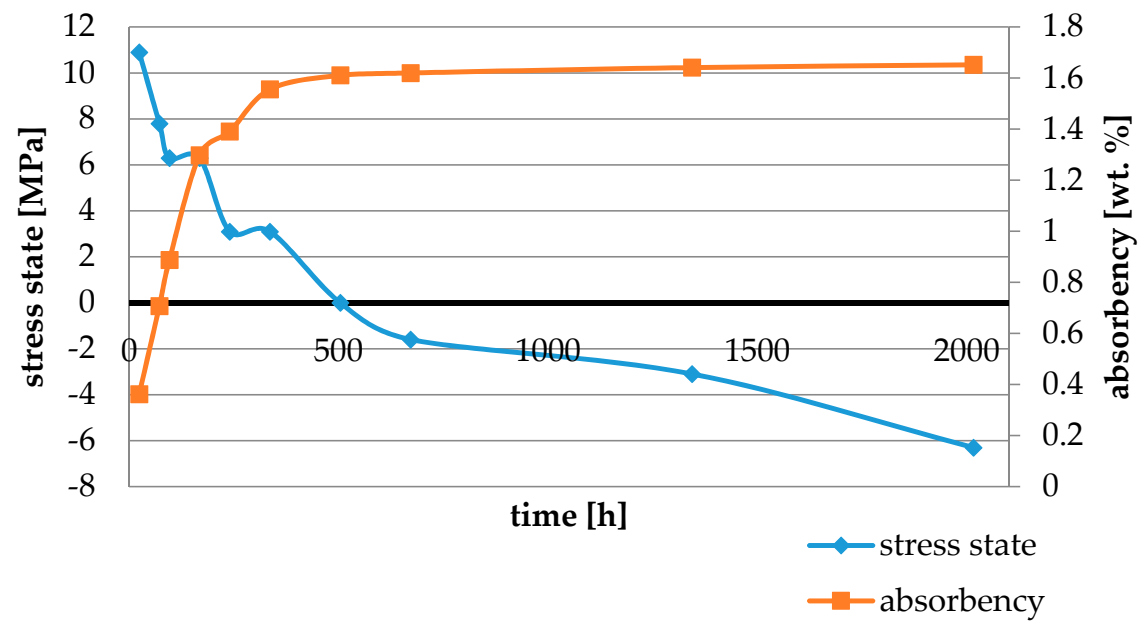

Figure 10. The influence of water sorption (2016 h water ageing) on the absorbency and contraction stress generated during the photopolymerization of Maxcem Elite Chroma. 


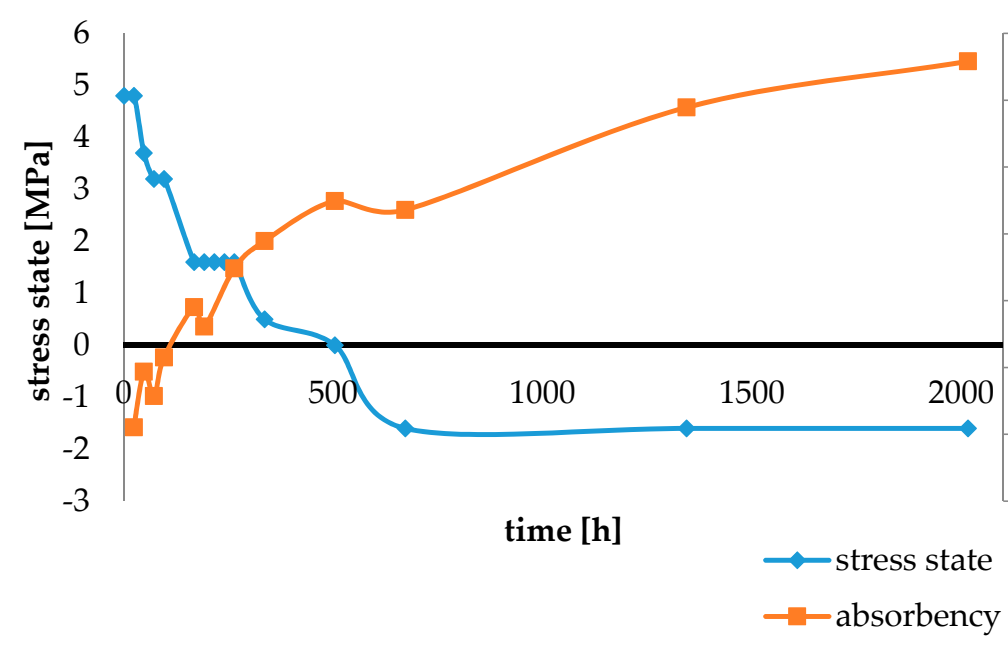

Figure 11. The influence of water sorption (2016 h water ageing) on the absorbency and contraction stress generated during the photopolymerization of Panavia SA Plus.

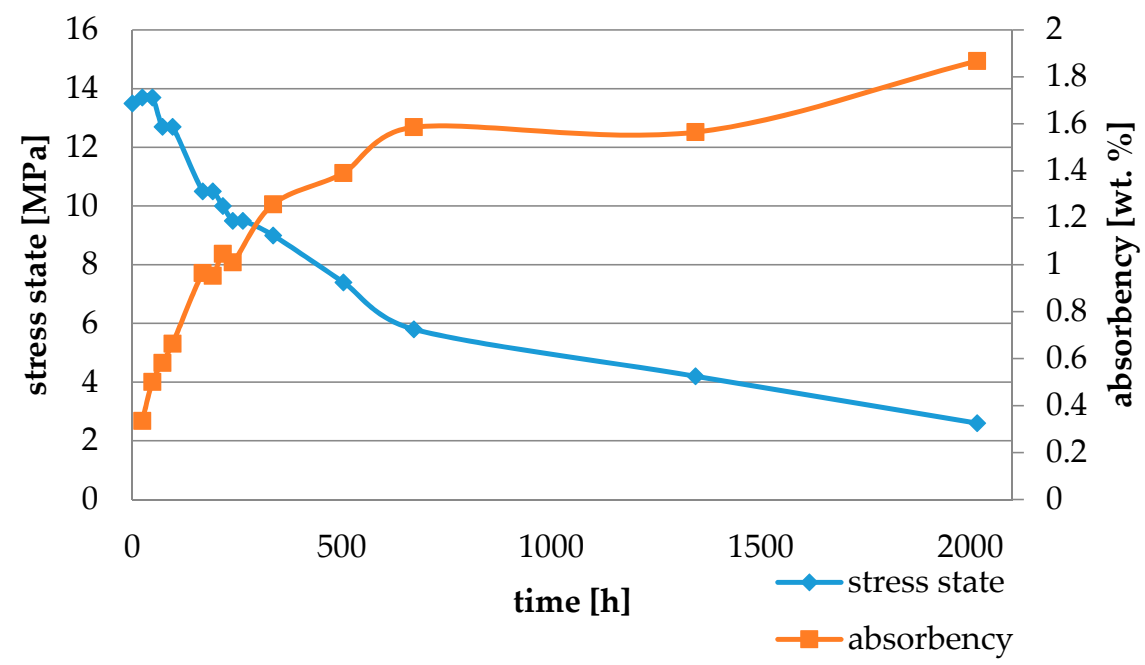

Figure 12. The influence of water sorption (2016 h water ageing) on the absorbency and contraction stress generated during the photopolymerization of Rely U200.

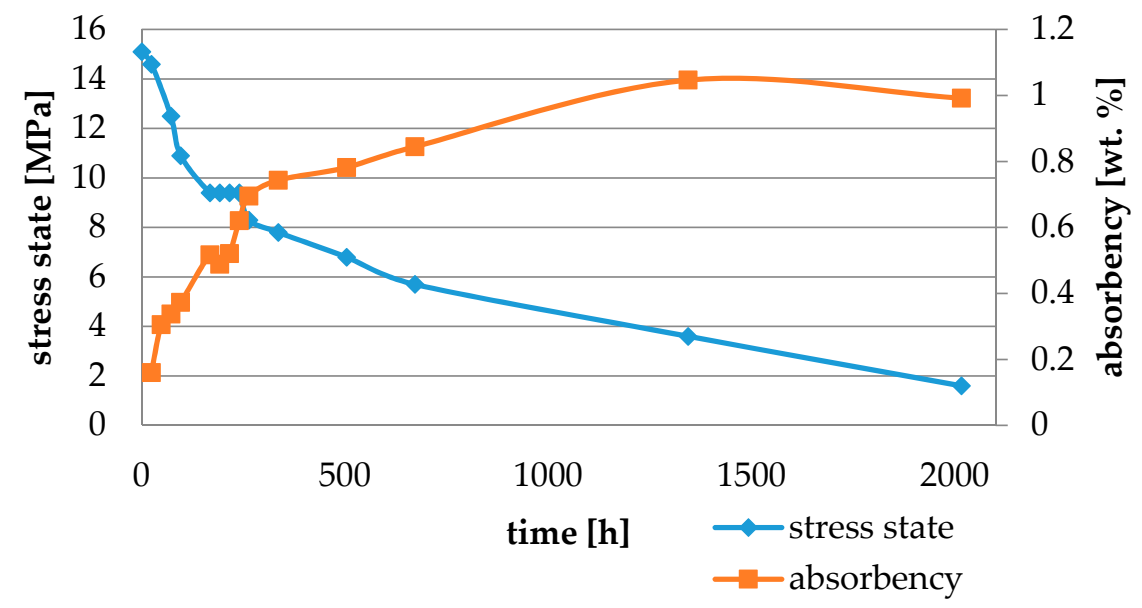

Figure 13. The influence of water sorption (2016 h water ageing) on the absorbency and contraction stress generated during the photopolymerization of SmartCem 2. 


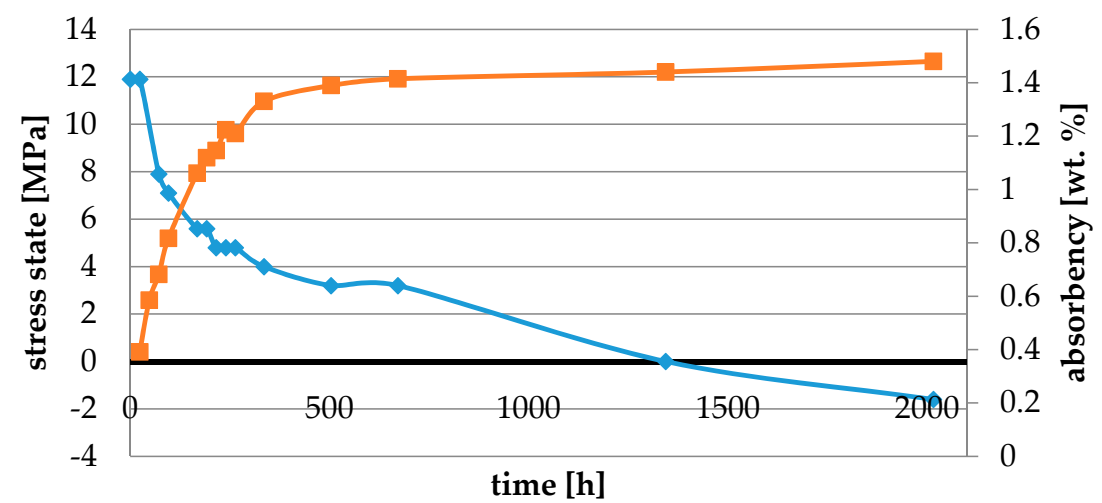

$\longrightarrow$ stress state
- absorbency

Figure 14. The influence of water sorption (2016 h water ageing) on the absorbency and contraction stress generated during the photopolymerization of SpeedCEM Plus.

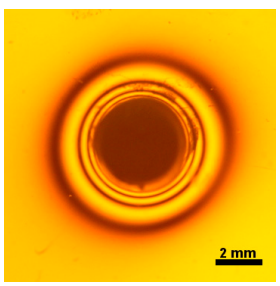

$0.5 \mathrm{~h}$

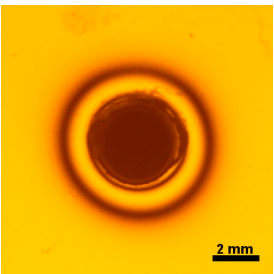

$336 \mathrm{~h}$

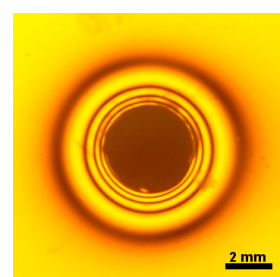

$24 \mathrm{~h}$

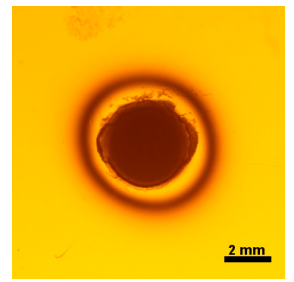

$504 \mathrm{~h}$

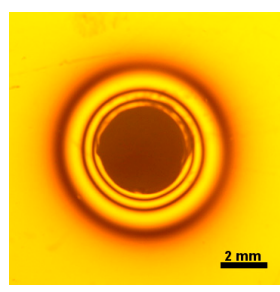

$96 \mathrm{~h}$

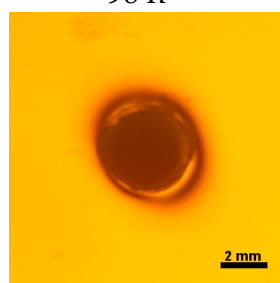

$672 \mathrm{~h}$

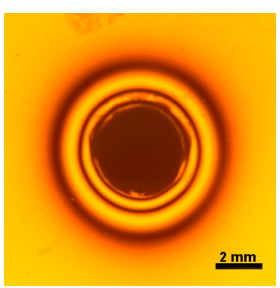

$168 \mathrm{~h}$

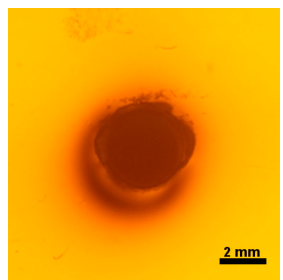

$1344 \mathrm{~h}$

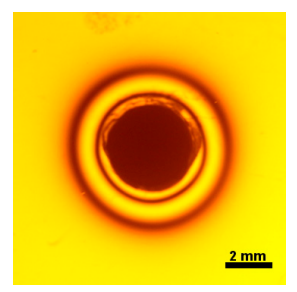

$240 \mathrm{~h}$

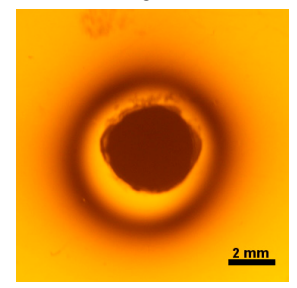

2016 h

Figure 15. Isochromes in an epoxy plate around Maxcem Elite Chroma restoration before and after water storage; $0.5-2016 \mathrm{~h}$.

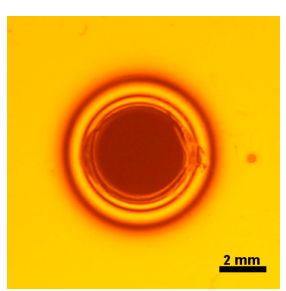

$0.5 \mathrm{~h}$

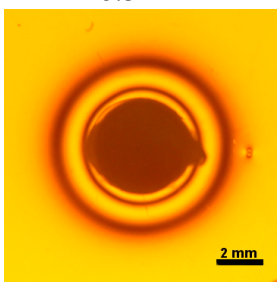

$336 \mathrm{~h}$

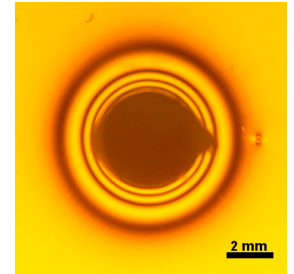

$24 \mathrm{~h}$

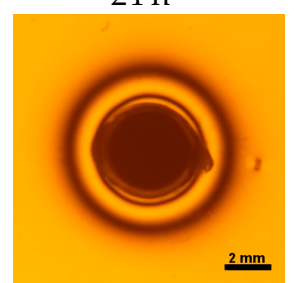

$504 \mathrm{~h}$

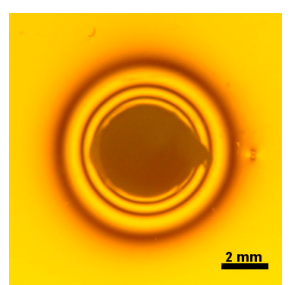

$96 \mathrm{~h}$

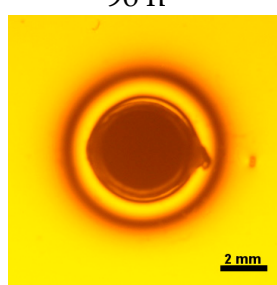

$672 \mathrm{~h}$

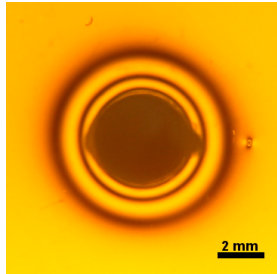

$168 \mathrm{~h}$

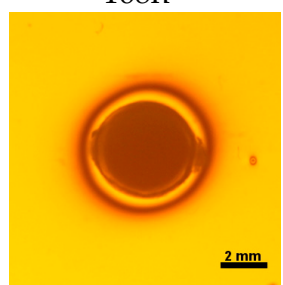

$1344 \mathrm{~h}$

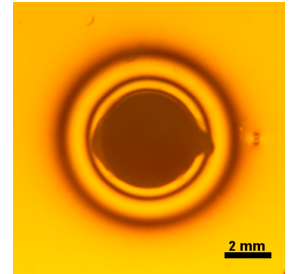

$240 \mathrm{~h}$

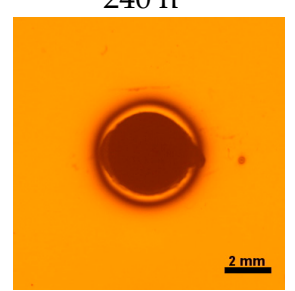

$2016 \mathrm{~h}$

Figure 16. Isochromes in an epoxy plate around NX3 restoration before and after water storage; 0.5-2016 h. 
The lowest contraction stress from tested materials exhibited Panavia SA Plus. The contraction stress decreased from 4.8 up to $0.0 \mathrm{MPa}$ after $504 \mathrm{~h}$ (21 days) of water conditioning (Figure 11). Further water ageing resulted in additional stress: after $2016 \mathrm{~h}$ (84 days) stress level increased up to $-1.6 \mathrm{MPa}$ (Figure 11).

The highest contraction stress was observed for SmartCem 2 amounting up to $15.1 \mathrm{MPa}$. The contraction stress of SmartCem 2 after 2016 h (84 days) of water storage reduced up to $1.6 \mathrm{MPa}$ (Figure 13).

\section{Discussion}

High configuration factor (C-factor) and the low viscosity of resin cements may generate relatively high contraction stress. This stress may cause debonding of the luting material, thereby increasing microleakage [14]. Our previous study (using an epoxy resin plate) [18,24], demonstrated that the photoelastic method can be used to evaluate the effect of water sorption on stress reduction at the tooth-restoration interface. This method shows that the contraction stress of dental resins may be partially relieved by the water uptake [18]. However, the in-depth analysis of the shrinkage stress values in various resin cement materials after water ageing is also highly demanded.

The overall results showed the development of the initial stress in the compressive direction during photopolymerization. The composition of resin cements affected the sorption and solubility processes which, in turn, exerted influence on the hygroscopic expansion and plasticization. Thus, the compensatory effect was composition-dependent [26]. This study confirmed the lower water sorption for composite resin cements as compared with self-adhesive resin cements that underwent water ageing. The presence of hydroxyl, carboxyl, and phosphate groups in monomers made them more hydrophilic and, supposedly, more prone to water sorption [27].

Variolink Esthetic DC and NX3 do not contain adhesive monomers. In the present study they exhibited sorption similar to composite materials [18]. Variolink Esthetic DC showed a high solubility value and the lowest decrease in contraction stress (of about 70\%). The water immersion of resin materials might result in dissolving and leaching of some components (unreacted monomers or fillers) out of the material [28]. Variolink Esthetic DC contains a modified polymer matrix and nanofiller. The lowest contraction stress might result from a small hydrolysis and plasticization effect of the modified resin matrix.

Cement It is a composite resin cement which, in comparison with NX3 and Variolink Esthetic DC, showed higher values of water sorption and its total value of stress changes was $12.5 \mathrm{MPa}$. This could be explained by the composition of the polymer matrix containing bis-GMA and HDDMA. These monomers showed comparable characteristics: high water sorption values $[29,30]$, similar polymer networks, and susceptibility to hydrolysis [31].

The four tested materials did not meet the requirements of ISO 4049, as they showed sorption values above $40 \mu \mathrm{g} / \mathrm{mm}^{3}$ (Breeze and MaxCem Elite Chroma) or the solubility value above $7.5 \mu \mathrm{g} / \mathrm{mm}^{3}$ (Variolink Esthetic DC and Panavia 2.0). The differences in water absorption of the polymer network depending on monomer type were reported. The highest water sorption was observed for MaxCem Elite Chroma (Figure 15). This material consists of HEMA and GDM that have one of the highest hydrophilicities among dental resins. HEMA was shown to induce water sorption, leading to the expansion of the polymer matrix [32]. Resin-modified glass-ionomer cements (RMGICs) absorbed more water due to hydroxyethyl methacrylate content, present in the hydrogel form in the polymerized matrices [33]. HEMA might be present either as a separate component or a grafted component into the structure of the polyacrylic acid backbone. The polymerized matrices of these materials were very hydrophilic and might include an interpenetrating network of poly(HEMA), copolymers of grafted HEMA, and polyacid salts that were more prone to water uptake [34]. Park et al. [35] showed that GDM exhibited the highest water sorption in comparison to bis-GMA, HEMA, EGDM, DEGDM, TEGDMA, GDM, and GTM. In the present study, the decrease in contraction stress after $2016 \mathrm{~h}$ ( 84 days) of water immersion varied significantly between tested materials. Figures 2-16 showed that the expansion 
dynamics also differed substantially. All studied materials exhibited contraction stress relief during water immersion. The value of stress decreased up to $0 \mathrm{MPa}$ in different times depending on the material and its composition.

To sum up, the phenomenon of hydroscopic expansion after compensation of contraction stress should be emphasized more and evaluated. Such over-compensation could lead to internal expansion stress [36]. Hygroscopic stress could result in micro-cracks or even cusp fractures in the restored tooth [37], poorer mechanical properties [38,39], hydrolytic degradation of bonds particularly at the resin-filler interface [40], polymer plasticization leading to hardness reduction and glass transition temperature [40], and impaired wear resistance [41]. Excessive water sorption is not desired as it causes an outward movement of residual monomers and ions due to material solubility. Furthermore, water sorption might generate peeling stress in bonded layers of polymers that may cause serious clinical consequences [42], which may occur especially when prosthetic restorations are adhesively cemented [42].

The present study demonstrated that self-adhesive cements, i.e., Maxcem Elite Chroma, Speed Cem Plus, Cement It, Panavia SA Plus, Breeze, and Panavia 2.0 exhibited high stress values due to water expansion (from 0 up to almost $7 \mathrm{MPa}$ ). Water expansion stress of Maxcem Elite Chroma and Breeze amounted to up to $\sim 6-7 \mathrm{MPa}$ which could be associated with their composition, particularly with acidic monomer 4-MET in Breeze and HEMA, and GDM and tetramethylbutyl hydroperoxide in Maxcem Elite Chroma. The monomers, mentioned above, were responsible for water uptake and stress built-up associated with hydroscopic expansion [35]. According to the literature such high stress values were not desirable. Huang et al. [33] found that a giomer material exhibited extensive hygroscopic expansion (due to osmotic effect) enabling enclosing glass cylinders to crack after two weeks of immersion in water. Cusp fracture in endodontically-treated teeth was attributed to hygroscopic expansion of a temporary filling material [33], while cracks in all-ceramic crowns were associated with hygroscopic expansion of compomer and resin-modified glassionomer materials used as core build-up and/or luting cements [33]. Three-year clinical performance study also suggested hygroscopic expansion as a possible cause of cusp fracture in 19\% of teeth restored with an ion-releasing composite [43].

Thus, the positive influence of water sorption on contraction stress relief in the case of luting cements, particularly self-adhesive materials, should be considered carefully. Shrinkage occurred within seconds, but water sorption took days and weeks. The rate of hygroscopic shear stress relief depended on the resin volume and its accessibility to water [11]. The contraction stress relief rates observed in luting resin cements could be much lower than in composite resin restorative materials. The composite restorations usually have a relatively large surface exposed to water in comparison to the overall surface of the luting material. As far as luting cements are concerned, the surface exposed to oral fluids is extremely small, while the pathway is extremely long. The consequences (slower compensation of contraction stress) might be less severe if water sorption is also possible from the dentin (dentin exposed to oral environment) [26].

The precise effect of water absorption depends on many factors including not only the material characteristics, the rate and amount of water absorbed, but also the mechanism of absorption [44]. Absorption leads to dimensional changes and has potentially important clinical implications. The positive effect of water absorption on composite restorative materials can be described as the mechanism for the compensation of polymerization shrinkage and the relaxation of stress. In clinical conditions, water absorption may help in the closure of contraction gaps around composite filling materials. It is worth emphasizing that the absorption can, in some cases, result in significant hydroscopic expansion and, thus, be damaging to the resin material and bonded tooth structure.

\section{Conclusions}

Among all studied resin cements, self-adhesive cements exhibited the highest water sorption due to acid monomer content, which affected the formation of hydroscopic expansion stress. The presence 
of this type of stress might pose a threat to prosthetic restorations. Therefore, there is still a need for research that would precisely illustrate the generated stress in clinical conditions.

Tested resin cements generated differentiated contraction stress during photopolymerization. The dynamic of hydroscopic compensation (resulting from water sorption) or over-compensation of the contraction stress is also material characteristic-dependent.

Author Contributions: M.-L.S., K.B., and J.S. conceived and designed the experiments; A.S., B.L., and K.K. performed the experiments; M.D. and G.S. analyzed the data; and G.S., A.S., and K.B. wrote the paper.

Funding: The financial support of this work by Medical University of Lodz, Poland (grant no. 502-03/2-148-03/502-24-075) is gratefully acknowledged.

Conflicts of Interest: The authors declare no conflict of interest. The founding sponsors had no role in the design of the study; in the collection, analyses, or interpretation of data; in the writing of the manuscript; or in the decision to publish the results.

\section{References}

1. Christensen, G.J. Why use resin cements? J. Am. Dent. Assoc. 2010, 141, 204-206. [CrossRef] [PubMed]

2. Diaz-Arnold, A.M.; Vargas, M.A.; Haselton, D.R. Current status of luting agents for fixed prosthodontics. J. Prosthet. Dent. 1999, 81, 135-141. [CrossRef]

3. Radovic, I.; Monticelli, F.; Goracci, C.; Vulicevic, Z.R.; Ferrari, M. Self-adhesive resin cements: A literature review. J. Adhes. Dent. 2008, 10, 251-258. [CrossRef] [PubMed]

4. Sunico-Segarra, M.; Segarra, A. A Practical Clinical Guide to Resin Cements; Springer: Berlin/Heidelberg, Germany, 2015; pp. 9-23.

5. Rawls, H.R.; Shen, C.; Anusavice, K.J. Dental Cements. In Phillips' Science of Dental Materials; Saunders: Philadelphia, PA, USA, 2013; pp. 307-339.

6. Hill, E.E.; Lott, J. A clinically focused discussion of luting materials. Aust. Dent. J. 2011, 56 (Suppl. S1), 67-76. [CrossRef] [PubMed]

7. El-Mowafy, O. The use of resin cements in restorative dentistry to overcome retention problems. J. Can. Dent. Assoc. 2001, 67, 97-102. [PubMed]

8. Vrochari, A.D.; Eliades, G.; Hellwig, E.; Wrbas, K.T. Curing efficiency of four self-etching, self-adhesive resin cements. Dent. Mater. 2009, 25, 1104-1108. [CrossRef] [PubMed]

9. Turkistani, A.; Sadr, A.; Shimada, Y.; Nikaido, T.; Sumi, Y.; Tagami, J. Sealing performance of resin cements before and after thermal cycling: Evaluation by optical coherence tomography. Dent. Mater. 2014, 30, 993-1004. [CrossRef] [PubMed]

10. Hitz, T.; Stawarczyk, B.; Fischer, J.; Hämmerle, C.H.F.; Sailer, I. Are self-adhesive resin cements a valid alternative to conventional resin cements? A laboratory study of the long-term bond strength. Dent. Mater. 2012, 28, 1183-1190. [CrossRef] [PubMed]

11. Feilzer, A.J.; De Gee, A.J.; Davidson, C.L. Increased Wall-to-Wall Curing Contraction in Thin Bonded Resin Layers. J. Dent. Res. 1989, 68, 48-50. [CrossRef] [PubMed]

12. Al Sunbul, H.; Silikas, N.; Watts, D.C. Polymerization shrinkage kinetics and shrinkage-stress in dental resin-composites. Dent. Mater. 2016, 32, 998-1006. [CrossRef] [PubMed]

13. Spinell, T.; Schedle, A.; Watts, D.C. Polymerization shrinkage kinetics of dimethacrylate resin-cements. Dent. Mater. 2009, 25, 1058-1066. [CrossRef] [PubMed]

14. Frassetto, A.; Navarra, C.O.; Marchesi, G.; Turco, G.; Di Lenarda, R.; Breschi, L.; Ferracane, J.L.; Cadenaro, M. Kinetics of polymerization and contraction stress development in self-adhesive resin cements. Dent. Mater. 2012, 28, 1032-1039. [CrossRef] [PubMed]

15. Shiozawa, M.; Takahashi, H.; Asakawa, Y.; Iwasaki, N. Color stability of adhesive resin cements after immersion in coffee. Clin. Oral Investig. 2015, 19, 309-317. [CrossRef] [PubMed]

16. Petropoulou, A.; Vrochari, A.D.; Hellwig, E.; Stampf, S.; Polydorou, O. Water sorption and water solubility of self-etching and self-adhesive resin cements. J. Prosthet. Dent. 2015, 114, 674-679. [CrossRef] [PubMed]

17. Marghalani, H.Y. Sorption and solubility characteristics of self-adhesive resin cements. Dent. Mater. 2012, 28, e187-e198. [CrossRef] [PubMed] 
18. Bociong, K.; Szczesio, A.; Sokolowski, K.; Domarecka, M.; Sokolowski, J.; Krasowski, M.; Lukomska-szymanska, M. The Influence of Water Sorption of Dental Light-Cured Composites on Shrinkage Stress. Materials 2017, 10, 1142. [CrossRef] [PubMed]

19. Stomatologia-Materiały Polimerowe do Odbudowy; PN-EN ISO 4049:2010; Polski Komitet Normalizacyjny: Warszawa, Poland, 2010.

20. Li, L.; Chen, M.; Zhou, X.; Lu, L.; Li, Y.; Gong, C.; Cheng, X. A case of water absorption and water/fertilizer retention performance of super absorbent polymer modified sulphoaluminate cementitious materials. Constr. Build. Mater. 2017, 150, 538-546. [CrossRef]

21. Müller, J.A.; Rohr, N.; Fischer, J. Evaluation of ISO 4049: Water sorption and water solubility of resin cements. Eur. J. Oral Sci. 2017, 125, 141-150. [CrossRef] [PubMed]

22. Bociong, K. Naprężenia skurczowe generowane podczas fotoutwardzania eksperymentalnego kompozytu stomatologicznego. Cz. II. Przem. Chem. 2017, 1, 72-74. [CrossRef]

23. Bociong, K.; Krasowski, M.; Domarecka, M.; Sokołowski, J. Wpływ metody fotopolimeryzacji kompozytów stomatologicznych na bazie zywic dimetakrylanowych na napręzenia skurczowe oraz wybrane właściwości utwardzonego materiału. Polimery 2016, 61, 499-508. [CrossRef]

24. Domarecka, M.; Sokołowski, K.; Krasowski, M.; Szczesio, A.; Bociong, K.; Sokołowski, J.; Łukomska-Szymańska, M. Influence of water sorption on the shrinkage stresses of dental composites. J. Stomatol. 2016, 69, 412-419.

25. Timoshenko, S.; Goodier, J.N. Theory of Elasticity, 2nd ed.; McGraw-Hill: New York, NY, USA, 1951.

26. Feilzer, A.J.; de Gee, A.J.; Davidson, C.L. Relaxation of polymerization contraction shear stress by hygroscopic expansion. J. Dent. Res. 1990, 69, 36-39. [CrossRef] [PubMed]

27. Santerre, J.P.; Shajii, L.; Leung, B.W. Relation of dental composite formulations to their degradation and the release of hydrolyzed polymeric-resin-derived products. Crit. Rev. Oral Biol. Med. 2001, 12, 136-151. [CrossRef] [PubMed]

28. Mahajan, R.P.; Shenoy, V.U.; MV, S.; Walzade, P.S. Comparative Evaluation of Solubilities of Two Nanohybrid Composite Resins in Saliva Substitute and Distilled Water: An in vitro Study. J. Contemp. Dent. 2017, 7, $82-85$.

29. Siswomihardjo, W.; Sunarintyas, S.; Matinlinna, J.P. The influence of resin matrix on the water sorption of fiber-reinforced composites for DENTAL use. J. Eng. Appl. Sci. 2016, 11, 2678-2682.

30. Sideridou, I.; Tserki, V.; Papanastasiou, G. Study of water sorption, solubility and modulus of elasticity of light-cured dimethacrylate-based dental resins. Biomaterials 2003, 24, 655-665. [CrossRef]

31. Ling, L.; Xu, X.; Choi, G.Y.; Billodeaux, D.; Guo, G.; Diwan, R.M. Novel F-releasing composite with improved mechanical properties. J. Dent. Res. 2009, 88, 83-88. [CrossRef] [PubMed]

32. Malacarne, J.; Carvalho, R.M.; de Goes, M.F.; Svizero, N.; Pashley, D.H.; Tay, F.R.; Yiu, C.K.; de Oliveira Carrilho, M.R. Water sorption/solubility of dental adhesive resins. Dent. Mater. 2006, 22, 973-980. [CrossRef] [PubMed]

33. Huang, C.; Kei, L.; Wei, S.H.Y.; Cheung, G.S.P.; Tay, F.R.; Pashley, D.H. The influence of hygroscopic expansion of resin-based restorative materials on artificial gap reduction. J. Adhes. Dent. 2002, 4, 61-71. [PubMed]

34. Wilson, A.D. Resin-modified glass-ionomer cements. Int. J. Prosthodont. 1990, 3, 425-429. [PubMed]

35. Park, J.; Eslick, J.; Ye, Q.; Misra, A.; Spencer, P. The influence of chemical structure on the properties in methacrylate-based dentin adhesives. Dent. Mater. 2013, 31, 1713-1723. [CrossRef] [PubMed]

36. Wei, Y.J.; Silikas, N.; Zhang, Z.T.; Watts, D.C. Diffusion and concurrent solubility of self-adhering and new resin-matrix composites during water sorption/desorption cycles. Dent. Mater. 2011, 21, 97-205. [CrossRef] [PubMed]

37. Rüttermann, S.; Krüger, S.; Raab, W.H.M.; Janda, R. Polymerization shrinkage and hygroscopic expansion of contemporary posterior resin-based filling materials-A comparative study. J. Dent. 2007, 35, 806-813. [CrossRef] [PubMed]

38. Musanje, L.; Shu, M.; Darvell, B.W. Water sorption and mechanical behaviour of cosmetic direct restorative materials in artificial saliva. Dent. Mater. 2001, 17, 394-401. [CrossRef]

39. Bastioli, C.; Romano, G.; Migliaresi, C. Water sorption and mechanical properties of dental composites. Biomaterials 1990, 11, 219-223. [CrossRef]

40. Ferracane, J.L. Hygroscopic and hydrolytic effects in dental polymer networks. Dent. Mater. 2006, 22, 211-222. [CrossRef] [PubMed] 
41. Göhring, T.N.; Besek, M.J.; Schmidlin, P.R. Attritional wear and abrasive surface alterations of composite resin materials in vitro. J. Dent. 2002, 30, 119-127. [CrossRef]

42. Kalachandra, S.; Turner, D.T. Water sorption of polymethacrylate networks: Bis-GMA/TEGDM copolymers. J. Biomed. Mater. Res. 1987, 21, 329-338. [CrossRef] [PubMed]

43. Versluis, A.; Tantbirojn, D.; Lee, M.S.; Tu, L.S.; Delong, R. Can hygroscopic expansion compensate polymerization shrinkage? Part I. Deformation of restored teeth. Dent. Mater. 2011, 27, 126-133. [CrossRef] [PubMed]

44. McCabe, J.F.; Rusby, S. Water absorption, dimensional change and radial pressure in resin matrix dental restorative materials. Biomaterials 2004, 25, 4001-4007. [CrossRef] [PubMed]

(c) 2018 by the authors. Licensee MDPI, Basel, Switzerland. This article is an open access article distributed under the terms and conditions of the Creative Commons Attribution (CC BY) license (http:/ / creativecommons.org/licenses/by/4.0/). 